\title{
Performance evaluation of oil displacing agents for primary-minor layers of the Daqing Oilfield
}

\author{
Zhang Jian ${ }^{1,3}$, Wang Shuxia ${ }^{2}$, Lu Xiangguo ${ }^{2 *}$ and He Xianhua ${ }^{3}$ \\ ${ }^{1}$ School of Petroleum Engineering, China University of Petroleum, Beijing 102249, China \\ ${ }^{2}$ School of Petroleum Engineering, Northeast Petroleum University, Daqing, Heilongjiang 163318, China \\ ${ }^{3}$ Information Section, E\&D Research Institute of Daqing Oilfield, Daqing, Heilongjiang 163712, China \\ (C) China University of Petroleum (Beijing) and Springer-Verlag Berlin Heidelberg 2011
}

\begin{abstract}
A series of experiments were conducted to investigate the molecular coil dimension $\left(D_{\mathrm{h}}\right)$ and molecular configuration of partially hydrolyzed polyacrylamides (HPAM), surfactant/HPAM system, and a living polymer. Compatibility between the polymer coils and the porous media was evaluated by instrumental analysis and laboratory simulation methods. Meanwhile, the performance of chemical flooding was investigated. Results indicated that the $D_{\mathrm{h}}$ decreased with an increase in water salinity and increased with an increase in polymer concentration. In aqueous solution, the polymer presented threedimensional reticular configuration and exhibited a fractal structure characterized by self-similarity. The polymer in the surfactant/HPAM system was mainly in the form of "surfactant-polymer" complex compound and the living polymer had an irregular "flaky-reticular" configuration which resulted in relatively poor compatibility between the molecular coils and the porous media. The type of oil displacing agent and its slug size influenced the incremental oil recovery. For the same oil displacing agent, a larger slug size would lead to a better chemical flooding response. Given the final recovery efficiency and economic benefits, high-concentration polymer flooding was selected as the optimimal enhanced oil recovery (EOR) technique and the incremental recovery efficiency was forecast to be $20 \%$.
\end{abstract}

Key words: Primary-minor layers, molecular coil dimension, molecular configuration, compatibility

\section{Introduction}

In recent years, most of the main oilfields in China have shown extremely high water-cut levels and the task of stabilizing oil production and controlling water production is very difficult; and on the other hand, it becomes more and more difficult to discovery new oilfields in the short run. Sharp rises in crude oil consumption and international oil price leave the petroleum industry in China only one choice, which is tapping the old oilfields and enhancing the oil recovery efficiency from the primary-minor layers with serious changes in sedimentary process. Table 1 gives the reservoir classification in the Daqing Oilfield. The primaryminor layers in the Daqing Oilfield are characterized by smallscale channel sands, many thin sublayers, low permeability, and strong horizontal heterogeneity and vertical heterogeneity (Wang and Zhang, 1992; Guo et al, 2006; Dong et al, 2010). Study of field application of polymer flooding in the primaryminor layers of the Daqing Oilfield is still at the initial stage. Field tests and laboratory simulation experiments of polymer

*Corresponding author. email: luxiangg2003@yahoo.com.cn Received June 24, 2010 flooding in primary-minor layers have achieved significant success relying on mature research results of main layers and Class II layers (Li et al, 2000; Lu and Zhang, 2008; Steve and Randy, 2007; Shao et al, 2010; Shi et al, 2010). In particular, rapid progress has been made in the following aspects, such as the rate of polymer solution injected into the primaryminor layers (Yang and Song, 2006), reasonable injectionproduction ratio for polymer flooding ( $\mathrm{Li}$ and $\mathrm{Lu}, 2004$; Zhao, 2008) and combined development of Class II layers and primary-minor layers (Guan, 2006). Yet little research has been conducted on the selection of oil displacing agent and compatibility between the oil displacing agent and the porous media. In this paper, we measured the dimension of polymer molecular coils $\left(D_{\mathrm{h}}\right)$, observed the molecular structure of the polymer, and conducted core flooding tests to evaluate the performance of polymer used in the primary-minor layers, which provided a basis for optimized oil displacement design in the primary-minor layers.

\section{Experimental}

\subsection{Materials and preparation of samples}

Simulated oil used in experiments was prepared by 
Table 1 Reservoir classification in the Daqing Oilfield

\begin{tabular}{cccccc}
\hline \multicolumn{2}{c}{ Reservoir type } & Main sedimentary facies & $\begin{array}{c}\text { Thickness of } \\
\text { sublayers, } \mathrm{m}\end{array}$ & $\begin{array}{c}\text { Permeability } \\
\mu \mathrm{m}^{2}\end{array}$ & Stratigraphic position \\
\hline Main layers & I & Flood plains & $\geq 4.0$ & $\geq 0.40$ & Pu I 1-2 \\
\hline $\begin{array}{c}\text { Class II } \\
\text { layers }\end{array}$ & IIA & Distributary plains & $\geq 1.5$ & $\geq 0.30$ & Sa II 1-3, Sa III 1-7 \\
\cline { 2 - 6 } & IIB & Inner front of distributary plains & $\geq 0.7$ & $\geq 0.10$ & $\begin{array}{c}\text { SaII 4-16, Sa III 8-10 } \\
\text { Pu I 4-7, Pu II, Gao I 1-5 }\end{array}$ \\
\hline $\begin{array}{c}\text { Primary-minor } \\
\text { layers }\end{array}$ & III & $\begin{array}{c}\text { Inner and outer front of } \\
\text { distributary plains }\end{array}$ & $<1.0$ & $<0.15$ & Sa I, Gao I (except the Gao I1-5), Gao II, Gao III \\
\hline
\end{tabular}

blending kerosene with degassed crude oil from the No.1 Oil Production Plant of the Daqing Oilfield. The viscosity of the simulated oil was $10.0 \mathrm{mPa} \cdot \mathrm{s}$ at $45^{\circ} \mathrm{C}$.

The water used included high-salinity water (HSW) and low-salinity water (LSW) taken from the No. 1 Oil Production Plant of the Daqing Oilfield, whose quality analysis is listed in Table 2. In addition, the mixed water used was prepared by mixing LSW and HSW at a weight ratio of 1:1.

Table 2 Water quality analysis

\begin{tabular}{|c|c|c|c|c|c|c|c|c|}
\hline \multirow{2}{*}{ Water } & \multicolumn{7}{|c|}{ Composition, mg/L } & \multirow{2}{*}{$\begin{array}{c}\text { Total salinity } \\
\mathrm{mg} / \mathrm{L}\end{array}$} \\
\hline & $\mathrm{Ca}^{2+}$ & $\mathrm{Mg}^{2+}$ & $\mathrm{Na}^{+}$ & $\mathrm{CO}_{3}^{2-}$ & $\mathrm{HCO}_{3}^{-}$ & $\mathrm{Cl}^{-}$ & $\mathrm{SO}_{4}^{2-}$ & \\
\hline Low-salinity water & 34 & 24 & 231 & 90 & 225 & 89 & 36 & 729 \\
\hline High-salinity water & 33 & 7.3 & 1265 & 210 & 1708 & 780 & 9.6 & 4012 \\
\hline
\end{tabular}

The polymer products used in this study consisted of a series of partially hydrolyzed polyacrylamides (HPAM) with different degrees of hydrolysis and relative molecular weight, which was provided by the PetroChina Daqing Refining $\&$ Chemical Company. Their viscosity-average molecular weights $M_{\text {HPAM }}$ were $6 \times 10^{6}, 1.0 \times 10^{7}, 1.5 \times 10^{7}, 2.5 \times 10^{7}$, and $3.5 \times 10^{7}$, respectively; and their degrees of hydrolysis were $16.5 \mathrm{~mol} \%, 18.2 \mathrm{~mol} \%, 19.4 \mathrm{~mol} \%, 22.2 \mathrm{~mol} \%$, and $25.0 \mathrm{~mol} \%$. The surfactant used was a non-ionic surfactant with an active ingredient of $50 \%$, provided by the Hualongxiang Chemical Industry Co., Ltd. in the Daqing High-tech Industrial Development Zone. The living polymer, Type I and type III, was combined with different kinds of functional groups in the $\mathrm{C}-\mathrm{C}$ main chain with an active ingredient of $88 \%$, which was produced by the Shanghai Haibo Company. Its constitutional formula is presented as follows:

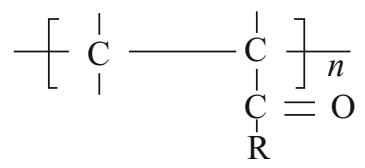

where $\mathrm{R}$ denotes $-\mathrm{NH}_{2},-\mathrm{ONa},-\mathrm{OR},-\mathrm{NHR},-\mathrm{RSO}_{3} \mathrm{Na}$, quaternary ammonium salt surfactant unit, $-(\mathrm{EO})_{n}(\mathrm{PO})_{m} \mathrm{R}$, cationic Gemini unit, - $\mathrm{RSH}$, etc.

Artificial core samples, $4.5 \mathrm{~cm} \times 4.5 \mathrm{~cm} \times 30 \mathrm{~cm}$ (height, width, length) were used to perform oil displacement tests. The core samples consisted of three sublayers, with permeabilities of $500 \times 10^{-3}, 130 \times 10^{-3}$, and $40 \times 10^{-3} \mu^{2}$, respectively. The permeability variation factor and the average gas permeability of the core samples were 0.72 and $220 \times 10^{-3} \mu \mathrm{m}^{2}$, respectively.

\subsection{Measurement of the dimensions of polymer coils in water}

The dimensions $\left(D_{\mathrm{h}}\right)$ of polymer coils in water were measured at $45^{\circ} \mathrm{C}$ with a BI-200SM system (providing both dynamic light scattering (DLS) and static light scattering (SLS); Brookhaven Instruments Corp, USA). The main component of the BI-200SM system included a BI-9000AT digital autocorrelator and a signal processor. The data were processed with a CONTIN mathematical model. Before testing, the liquids were filtered through a $0.8 \mu \mathrm{m}$ Millipore filter and then placed in a sample bottle cleaned with a KQ3200DE numerical control ultrasonic cleaner.

\subsection{Measurement of the polymer molecular configuration}

The molecular configuration of polymer was examined with a scanning electron microscope (SEM, Hitachi Ltd., Tokyo, Japan, Model S-3400N) at room temperature. Samples were prepared at $-70{ }^{\circ} \mathrm{C}$ by freeze-drying the HPAM solution, surfactant/HPAM system and living polymer solution (type I and type III), respectively. Finally, the specimens were sputter-coated with gold and observed with the SEM, and typical areas were photographed.

The high-salinity water used in this test was filtered through a $1.2 \mu \mathrm{m}$ Milli-pore filter. The sample containers were cleaned with distilled water and then with the filtered water before use.

\subsection{Core flooding tests}

A schematic of the core flooding system is displayed in Fig. 1. The system included a pump, a pressure transducer, 
a core holder, a hand pump, and an intermediate container. Except the pump and the hand pump, other components were kept within a constant temperature cabinet at $45^{\circ} \mathrm{C}$. The core flooding procedures are described as follows:

1) The core was evacuated and then saturated with highsalinity water at room temperature to measure its pore volume.
2) The water-saturated core was saturated with simulated oil at $45^{\circ} \mathrm{C}$ to measure oil saturation.

3) Water was injected into the core and then the water flooding recovery efficiency was obtained.

4) A given volume of the displacing fluid was injected into the core, followed by water flooding until the water cut reached $98 \%$. The final recovery efficiency was calculated.

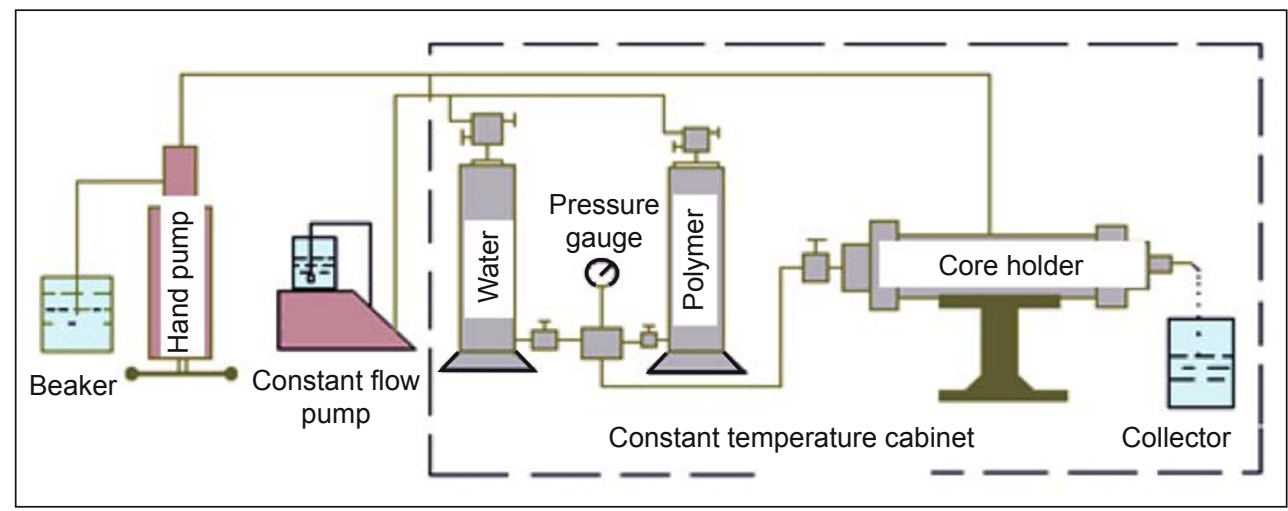

Fig. 1 Schematic of a core flooding system

\section{Results and discussion}

\subsection{Compatibility between oil displacing agent and porous media}

\subsubsection{The dimension of polymer coils}

The dimensions of polymer coils in the HPAM solution (listed in Table 3 ) shows that the water salinity and the molecular weight of HPAM influenced the dimensions of polymer coils in the displacing fluids. The polymers of higher molecular weight were of larger $D_{\mathrm{h}}$ when they dissolved in the same solvent. High-salinity water acted to reduce the $D_{\mathrm{h}}$ of polymer coils with the same molecular weight.

Table 3 Dimensions of polymer coils in the HPAM solution $\left(45^{\circ} \mathrm{C}\right)$

\begin{tabular}{cccc}
\hline \multirow{2}{*}{$\begin{array}{c}\text { Molecular weight } \\
\text { of HPAM } \\
M_{\text {HPAM }}\end{array}$} & \multicolumn{3}{c}{ Average $D_{\mathrm{h}}$ of polymer coils, nm } \\
\cline { 2 - 4 } & $\begin{array}{c}\text { Low-salinity } \\
\text { water }\end{array}$ & $\begin{array}{c}\text { Mixed } \\
\text { water }\end{array}$ & $\begin{array}{c}\text { High-salinity } \\
\text { water }\end{array}$ \\
\hline $6 \times 10^{6}$ & 427 & 355 & 301 \\
$1 \times 10^{7}$ & 507 & 409 & 342 \\
$1.5 \times 10^{7}$ & 579 & 461 & 413 \\
$2.5 \times 10^{7}$ & 654 & 532 & 504 \\
$3.5 \times 10^{7}$ & 1200 & 891 & 733 \\
\hline
\end{tabular}

Notes: HPAM concentration $C_{\text {HPAM }}$ was $200 \mathrm{mg} / \mathrm{L}$

The dimensions of polymer coils in the surfactant/HPAM system, which was prepared with high-salinity water, are shown in Table 4. A comparison between Tables 3 and 4 shows that the polymer coils in the surfactant/HPAM system had larger $D_{\mathrm{h}}$ value than those in the HPAM solution with the same water salinity and HPAM concentration.
Table 4 Dimensions of polymer coils in the surfactant/HPAM system $\left(45^{\circ} \mathrm{C}\right)$

\begin{tabular}{cc}
\hline $\begin{array}{c}\text { Molecular weight of HPAM } \\
M_{\mathrm{HPAM}}\end{array}$ & Average $D_{\mathrm{h}}$ of polymer coils, nm \\
\hline $6 \times 10^{6}$ & 502 \\
$1 \times 10^{7}$ & 558 \\
$1.5 \times 10^{7}$ & 669 \\
$2.5 \times 10^{7}$ & 749 \\
$3.5 \times 10^{7}$ & 1256 \\
\hline
\end{tabular}

Notes: In the surfactant/HPAM system, the HPAM concentration $C_{\text {HPAM }}$ was $200 \mathrm{mg} / \mathrm{L}$, and the surfactant concentration $C_{\mathrm{s}}$ was $400 \mathrm{mg} / \mathrm{L}$

The dimensions of polymer coils in the living polymer solution are listed in Table 5 . The dimension of the living polymer coils increased with an increase in the living polymer concentration. The $D_{\mathrm{h}}$ of "type I" living polymer coils was smaller than that of "type III" living polymer coils when the living polymer concentration was $800 \mathrm{mg} / \mathrm{L}$. The $D_{\mathrm{h}}$ of "type I" living polymer coils was larger than that of "type III" when the living polymer concentration was $1,200 \mathrm{mg} / \mathrm{L}$.

\subsubsection{Molecular configurations of oil displacing agents}

Figs. 2-5 show the SEM images of three oil displacing agent.

Figs. 2 and 3 indicate that the HPAM molecules showed a three-dimensional reticular configuration in the solution and exhibited fractal structures characterized by selfsimilarity. After the HPAM was partially hydrolyzed in the solution, there were carboxylic anions on the macromolecular chains. This generated some electrostatic repulsion between adjacent carboxylic groups and as a result the polymer coils expanded. Meanwhile, the molecular chains showed random configuration and different polymer molecular chains 
Table 5 Dimensions of polymer coils in the living polymer solution $\left(45^{\circ} \mathrm{C}\right)$

\begin{tabular}{cccccc}
\hline \multirow{2}{*}{$\begin{array}{c}\text { Living polymer concentration } \\
C_{\mathrm{p}}, \mathrm{mg} / \mathrm{L}\end{array}$} & \multicolumn{2}{c}{ Average $D_{\mathrm{h}}$ of Type I living polymer coils, $\mathrm{nm}$} & & \multicolumn{2}{c}{ Average $D_{\mathrm{h}}$ of Type III living polymer coils, $\mathrm{nm}$} \\
\cline { 2 - 3 } \cline { 5 - 6 } & Low-salinity water & High-salinity water & & Low-salinity water & High-salinity water \\
\hline 800 & 3101 & 2323 & 3696 & 3951 & 3112 \\
1000 & 5737 & 3647 & 7119 & 4253 & 3537 \\
1200 & 8774 & & & \\
\hline
\end{tabular}

intersected and entwined. As a result, a multilayer threedimensional reticular configuration was formed, with a very high density and many different-sized holes. In the reticular structure, there were thick trunks and thin branches. This type of reticular configuration had high support strength and could absorb a large number of water molecules to generate deformation resistance ( $Z$ hu et al, 2005; Cui et al, 2008), which presented strong ability to improve the viscosity of HPAM solution. Different molecular weight of polymer resulted in different molecular aggregation structures. The lower molecular weight gave shorter molecular chains and a sparse 3-D reticular configuration (as shown in Fig. 2).

Molecules in the surfactant/HPAM system aggregated to form a "flaky-reticular" structure (as shown in Fig. 4), which was different from the structure of polymer in the HPAM solution. Its trunks were much thicker than those in the HPAM solution and nearly flaky and the thin branches were similar to those in the HPAM solution. This may be explained as follows. In the surfactant/HPAM system, the nonionic surfactant dissolved in water through hydrogen bonding between the polar groups and water, but not ionization. Therefore, there were no charges and thus no electrostatic repulsion existed between surfactant molecules and HPAM. Moreover, there was weak interaction between polar groups and water molecules. The polar groups aggregated to form micelles (Dong et al, 2003) and then accumulated on (or combined with) the polymer molecular chains in the form of micellar aggregates. Therefore, the surfactant/HPAM system exhibited a "flaky-reticular" configuration.

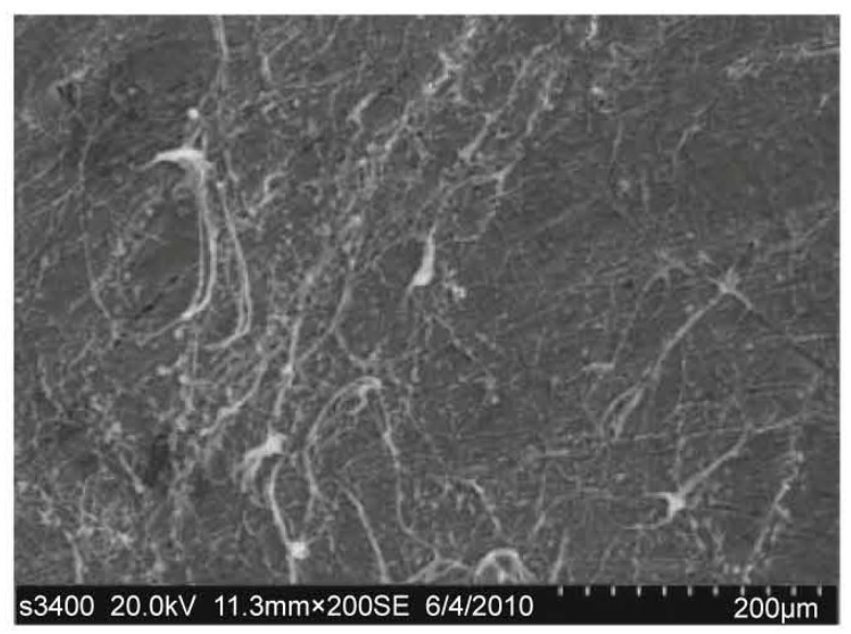

Fig. 2 SEM image of HPAM after freeze-drying $\left(M_{\mathrm{HPAM}}=1.0 \times 10^{7}, C_{\mathrm{HPAM}}=100 \mathrm{mg} / \mathrm{L}\right.$, room temperature $)$

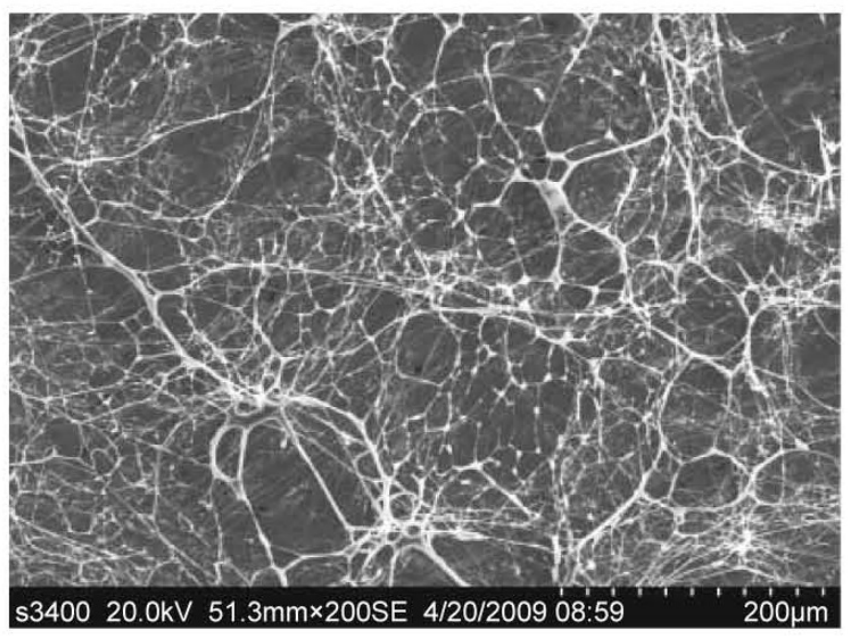

Fig. 3 SEM image of HPAM after freeze-drying $\left(M_{\mathrm{HPAM}}=2.5 \times 10^{7}, C_{\mathrm{HPAM}}=100 \mathrm{mg} / \mathrm{L}\right.$, room temperature $)$

For the living polymer (as shown in Fig. 5), its molecules were irregularly distributed in the solution and self-crosslinking occurred. The polymer molecules aggregated to form a "flaky-reticular" structure. This type of configuration had relatively poor 3-D reticulation and the molecules existed in the form of "aggregate-aggregate" complex aggregates. The flaky and the trunks were thicker than those of the HPAM aggregates. There were a few branches which were rarely coiled among different aggregates. This was because the living polymer may be prepared by physically covering

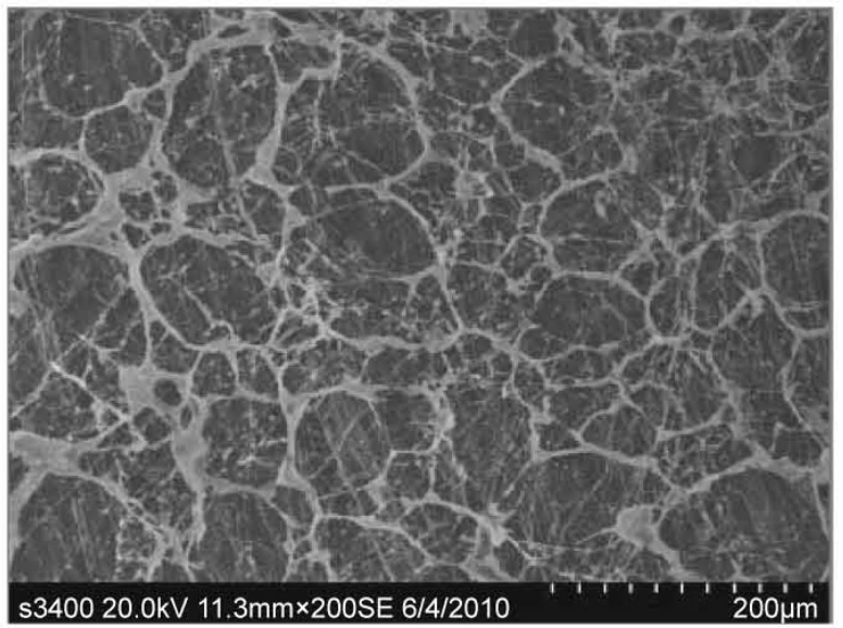

Fig. 4 SEM image of the dried surfactant/HPAM system $\left(M_{\mathrm{HPAM}}=2.5 \times 10^{7}, C_{\mathrm{HPAM}}=100 \mathrm{mg} / \mathrm{L}, C_{\mathrm{s}}=200 \mathrm{mg} / \mathrm{L}\right.$, room temperature $)$ 
the HPAM molecules with surfactant. Due to its self-crosslinking feature, the living polymer would easily aggregate, thus increasing the solution viscosity at a low concentration. However, the trunks in the aggregate structure were of different sizes, so the viscosity of the solution was not very stable.

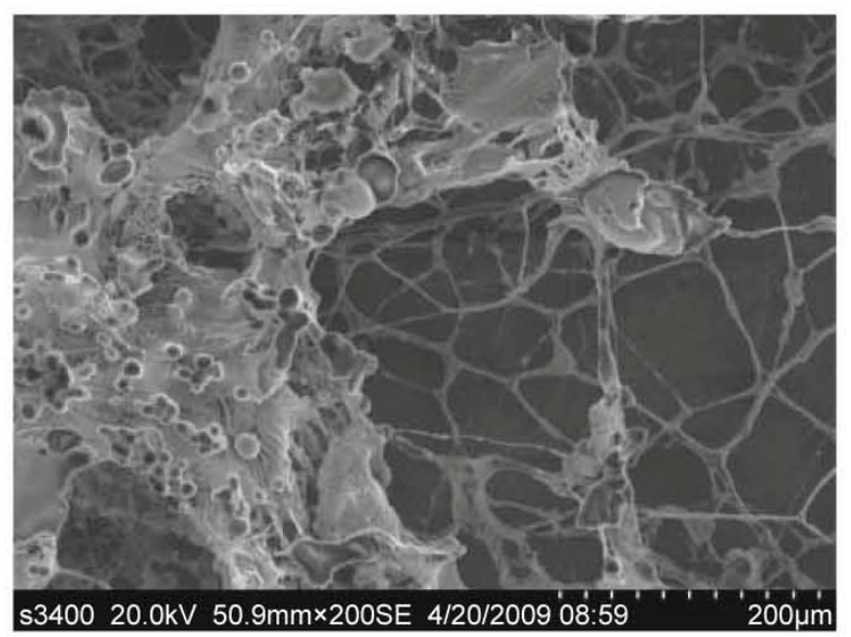

Fig. 5 SEM image of the living polymer (Type I) after freeze-drying $\left(C_{\mathrm{p}}=100 \mathrm{mg} / \mathrm{L}\right.$, room temperature $)$

\subsubsection{Molecular weight for primary-minor layers}

The lowest permeability of cores that polymer flowed through without face blocking and the relation between molecular weight and "median pore diameter $/ D_{\mathrm{h}}$ " can be determined by core flood results (see Figs. 6-8). Results indicated that the ratio (median pore diameter $/ D_{\mathrm{h}}$ ) ranged from 4 to 7 , when polymer molecules flowed through porous media without permanent blockage (see Fig. 9). Pore throat diameter was obtained by multiplying pore throat radius by 2 . The pore throat radius on a capillary pressure curve where the non-wetting fluid saturated $50 \%$ of the void space, was a good measure of the interconnected pore throats in a rock.

The lowest permeability, when the HPAM solution and the surfactant/HPAM system flowed through porous media without blockage, was summarized in Figs. 6 and 7, respectively. There was no definite approach to measure the molecular weight of the living polymer in the laboratory due to its self-cross-linking. So there was no fitted curve for the living polymer in this paper. The fitted curve of rock permeability versus pore throat radius of reservoirs in the Daqing Oilfield and the correlation equation were shown in Fig. 8. Substituting the lowest permeability value into the equation in Fig. 8 gave the pore throat radius. The pore throat radius was multiplied by 2 and then divided by $D_{\mathrm{h}}$. The results were shown in Fig. 9. Therefore, as long as the "median pore diameter $/ D_{\mathrm{h}}$ " ranged from 4 to 7 , the oil displacing agent would flow through the cores without blockage. If the lowest permeability of the primary-minor layers in the Daqing Oilfield was $40 \times 10^{-3} \mu^{2}$, the pore throat diameter calculated from the equation in Fig. 8 was $2,468 \mathrm{~nm}$. Results showed that the values of "median pore diameter $/ D_{\mathrm{h}}$ " of the high-concentration HPAM solution and the surfactant/HPAM

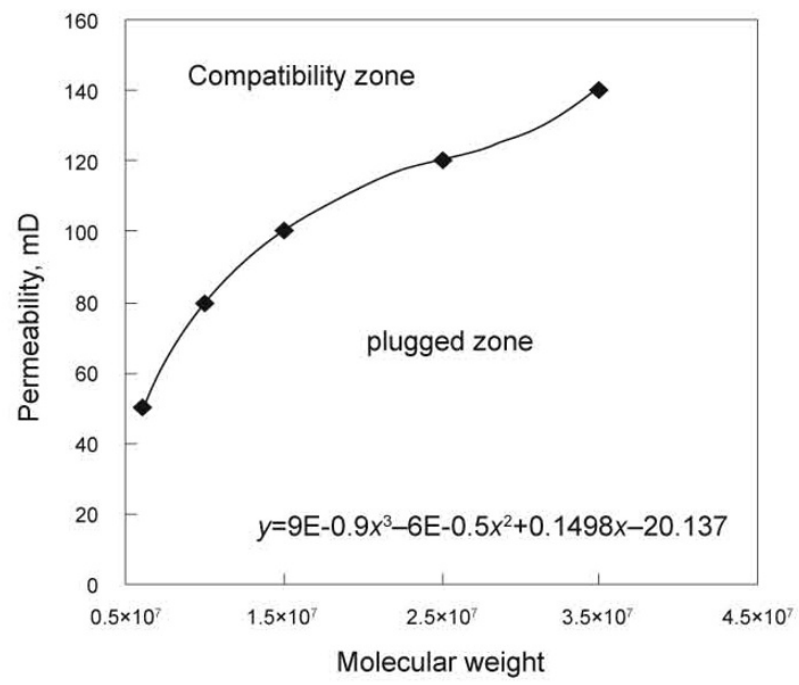

Fig. 6 Lowest permeability when the HPAM solution flowed through the cores without permanent blockage

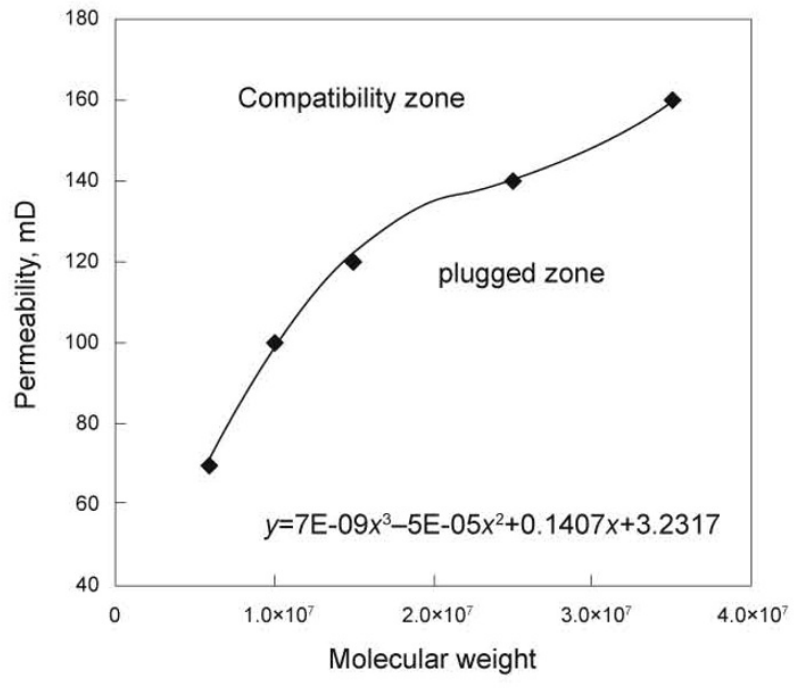

Fig. 7 Lowest permeability when the surfactant/HPAM system flowed through the cores without blockage

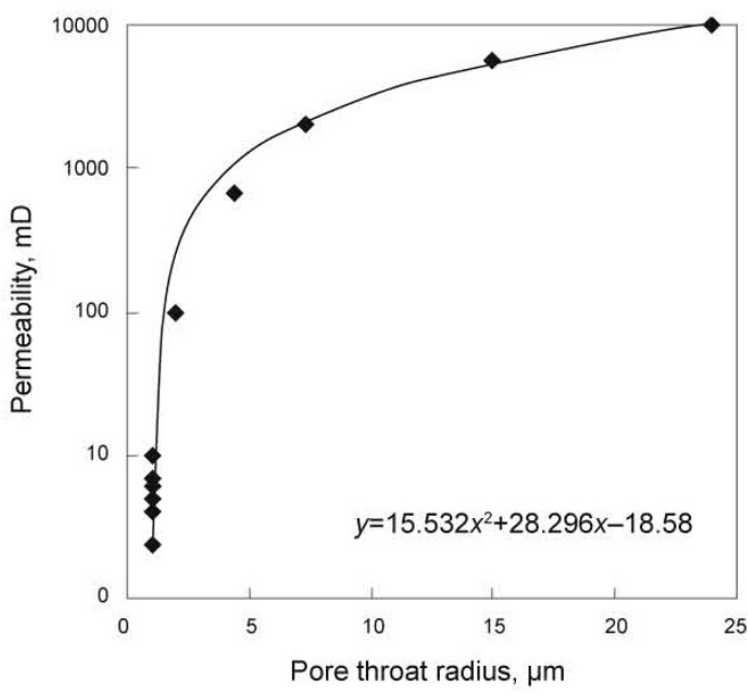

Fig. 8 Relationship between pore throat radius and permeability of reservoirs in the Daqing Oilfield 
system, whose molecular weight was $1.0 \times 10^{7}$, were 4.87 and 4.42 , respectively, which was in the range of 4-7 (other kinds of systems were not satisfying). This indicated that the compatibility between the polymer coils and the rock pores was relatively good and permanent blockage would not occur when the oil displacing agent flowed through the porous media.

To sum up, the molecular weight of promising oildisplacing agent was $1.0 \times 10^{7}$.

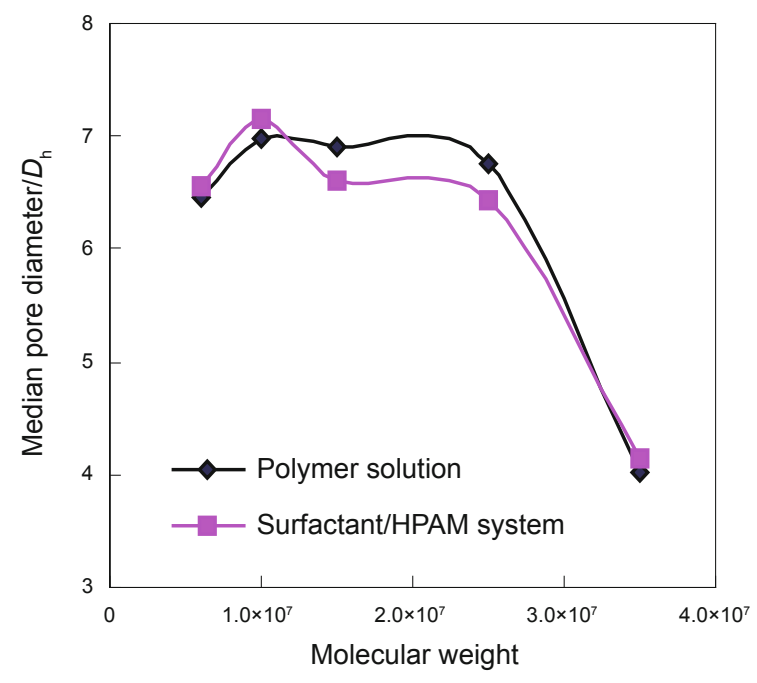

Fig. 9 Relationship between the relative molecular weight of polymer and the "median pore diameter $/ D_{\mathrm{h}}$ "

\subsection{Core flooding evaluation}

\subsubsection{Injection volume}

There were three types of displacing fluids: highconcentration HPAM solution (HPAM concentration was 1,500 mg/L), surfactant/HPAM system (surfactant: 3,000 mg/ L, HPAM: 1,200 mg/L), and the living polymer solution (800 $\mathrm{mg} / \mathrm{L}$ ). All of the displacing fluids were prepared with high salinity water in core flooding tests.
In the core flooding tests, 0.6875 pore volume $(\mathrm{PV})$ of the oil displacing agent was injected into the core at $0.3 \mathrm{~mL} / \mathrm{min}$. Experimental results are listed in Table 6.

Table 6 shows that the incremental oil recovery values were $22 \%$ original oil in place (OOIP) for the surfactant/ HPAM system, 21.2\% OOIP for the high-concentration HPAM solution, and $15.9 \%$ OOIP for the living polymer solution. According to proposed mechanisms with respect to chemical flooding, the surfactant/HPAM system had medium viscosity and the lowest injection pressure $(0.32 \mathrm{MPa})$, as shown in Fig. 10. The ultra-low interfacial tension (IFT, $2.68 \times 10^{-3} \mathrm{mN} / \mathrm{m}$ ) of the surfactant/HPAM system played an important role in enhancing displacement efficiency. The lower the IFT was, the higher the displacement efficiency was. So the surfactant/HPAM system had optimum enhanced oil recovery (EOR) when being injected at the same volume. Compared with the surfactant/HPAM system, the highconcentration HPAM solution had high viscosity and a strong ability of sweep improvement, but its displacement efficiency was not as high as the surfactant/HPAM system. Therefore, the EOR by HPAM flooding was worse than that by the surfactant/HPAM flooding. The incremental oil recovery increased by living polymer flooding was around $15.9 \%$ OOIP, which was the lowest value in the three core flooding tests. Because the molecules of the living polymer were of a "flaky- reticular" configuration with a large $D_{\mathrm{h}}$ and poor compatibility with reservoir rock, the polymer could not flow easily in the porous media. The face blocking resulted in a rapid rise in injection pressure (shown in Fig. 10). As more living polymer solution was injected into the core, the molecular chains of the living polymer partially began to stretch to break into short chains after the injection pressure reached a specific value, and so the short molecules entered the middle-low permeability layers. However, the ultimate recovery of oil displaced by the living polymer injection was unsatisfied because the molecular structure of the living polymer was damaged.

Table 6 Oil recovery efficiency of different oil displacing agents injected at the same volume $\left(45^{\circ} \mathrm{C}\right)$

\begin{tabular}{|c|c|c|c|c|c|c|c|}
\hline \multirow{2}{*}{$\begin{array}{c}\text { Scheme } \\
\text { No. }\end{array}$} & \multirow[b]{2}{*}{ Oil displacing fluid } & \multirow{2}{*}{$\begin{array}{c}\text { Viscosity of the } \\
\text { displacing fluid } \\
\mathrm{mPa} \cdot \mathrm{s}\end{array}$} & \multirow{2}{*}{$\begin{array}{c}\text { IFT between } \\
\text { displacing fluid and } \\
\text { Daqing crude oil, } \mathrm{mN} / \mathrm{m}\end{array}$} & \multirow{2}{*}{$\begin{array}{l}\text { Maximum pressure in } \\
\text { chemical flooding } \\
\mathrm{MPa}\end{array}$} & \multicolumn{2}{|c|}{ Recovery efficiency, \% } & \multirow{2}{*}{$\begin{array}{c}\text { Increment } \\
\%\end{array}$} \\
\hline & & & & & $\begin{array}{l}\text { Water } \\
\text { flooding }\end{array}$ & $\begin{array}{l}\text { Chemical } \\
\text { flooding }\end{array}$ & \\
\hline 1 & High-concentration HPAM solution & 22.9 & - & 0.42 & 44.1 & 65.3 & 21.2 \\
\hline 2 & Surfactant/HPAM system & 15.3 & $2.68 \times 10^{-3}$ & 0.32 & 43.5 & 66.3 & 22.2 \\
\hline 3 & Living polymer solution & 10.4 & - & 0.80 & 43.2 & 60.0 & 15.9 \\
\hline
\end{tabular}

Notes: 1) Oil displacing agent was injected into the core after the water cut of production fluids displaced by water reached $98 \%$.

2) The pore volume was $130.70 \mathrm{~cm}^{3}$ for Scheme $1,132.00 \mathrm{~cm}^{3}$ for Scheme 2, and $131.58 \mathrm{~cm}^{3}$ for Scheme 3.

\subsubsection{Chemicals costs}

In the core flooding tests mentioned in this section, all oil displacing agents injected had the same cost, equal to the cost of $0.6875 \mathrm{PV}$ of high-concentration polymer solution. Experimental results are summarized in Table 7 . The injection volume of corefloods 4 and 5 were determined by $0.6875 \mathrm{PV}$ of high concentration polymer solution with the same cost.

Table 7 indicates that the slug size of oil displacing agent influenced the enhanced oil recovery. At the same cost, the EOR of the high-concentration HPAM solution was the best, 


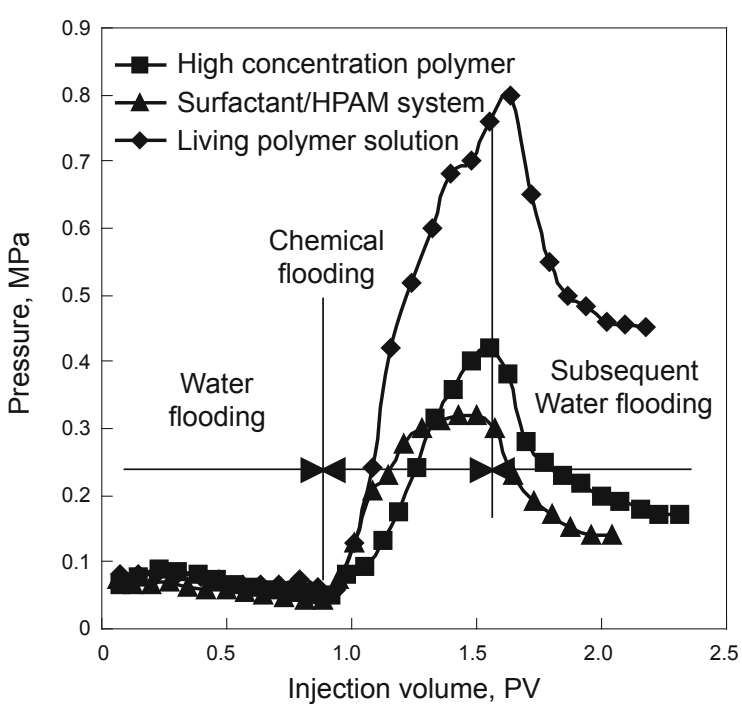

Fig. 10 Relationship between the injection pressure and the injection volume which was followed by the living polymer, and EOR of the surfactant/HPAM system was the poorest. Displacement mechanism analysis indicates that the surfactant/HPAM system had relatively high viscosity, which resulted in strong viscoelasticity (Xia et al, 2006). Moreover, the ultra-low IFT, on the order of $10^{-3} \mathrm{mN} / \mathrm{m}$, between the Daqing crude oil and the surfactant/HPAM system was achieved. Not only can the surfactant/HPAM system enlarge swept volume, but also it can enhance the recovery efficiency. Because of the high cost and small slug size, the EOR of surfactant/HPAM system was inferior to that of the living polymer, which had larger slug size. The high-concentration polymer had the best EOR, due to the highest viscosity, relatively high injection pressure, strong ability of enlarging swept volume, low cost, and moderate slug size. Besides, a comparison between Tables 6 and 7, for the same oil displacing agent, indicates that the larger the cumulative volume of oil displacing agent injected, the better the EOR.

Table 7 Recovery efficiency of different oil displacing agent with the same cost $\left(45^{\circ} \mathrm{C}\right)$

\begin{tabular}{|c|c|c|c|c|c|c|}
\hline \multirow[b]{2}{*}{ Scheme No. } & \multirow[b]{2}{*}{ Oil displacing fluid } & \multirow{2}{*}{$\begin{array}{l}\text { Viscosity of } \\
\text { the displacing } \\
\text { fluid, mPa.s }\end{array}$} & \multirow{2}{*}{$\begin{array}{c}\text { IFT between } \\
\text { displacing fluid and } \\
\text { Daqing crude oil, } \\
\mathrm{mN} / \mathrm{m}\end{array}$} & \multicolumn{2}{|c|}{ Recovery efficiency, \% } & \multirow{2}{*}{$\begin{array}{c}\text { Increment } \\
\%\end{array}$} \\
\hline & & & & $\begin{array}{l}\text { Water } \\
\text { flooding }\end{array}$ & $\begin{array}{l}\text { Chemical } \\
\text { flooding }\end{array}$ & \\
\hline 1 & 0.6875 PV high-concentration HPAM solution & 22.9 & - & 44.1 & 65.3 & 21.2 \\
\hline 4 & $0.2080 \mathrm{PV}$ surfactant/HPAM system & 15.3 & $2.68 \times 10^{-3}$ & 43.2 & 57.5 & 13.4 \\
\hline 5 & 1.1730 PV living polymer solution & 10.4 & - & 44.2 & 63.0 & 18.9 \\
\hline
\end{tabular}

Notes: 1) Oil displacing agent was injected into the core after the water cut of production fluids displaced by water reached $98 \%$.

2) The pore volume was $125.14 \mathrm{~cm}^{3}$ for Scheme 4 and $128.68 \mathrm{~cm}^{3}$ for Scheme 5.

\section{Conclusions}

1) The molecular dimensions of oil displacing agent in water were affected by the water salinity and the polymer molecular weight. The polymer dimensions increased with a decrease in water salinity and an increase in molecular weight.

2) The pore throat diameter of primary-minor layers without blockage can be determined by fitted curve of rock permeability versus pore throat radius of the reservoir, factors influencing $D_{\mathrm{h}}$, and geological characteristics of primaryminor layers. The preferred oil displacing agent, suitable for primary-minor layers, had a molecular weight of $10 \times 10^{6}$.

3) The special "flaky-reticular" configuration of the living polymer and poor compatibility between the living polymer and primary-minor layers resulted in high injection pressure and unfavorable recovery efficiency.

4) With the same cost of oil displacing agents, the enhanced oil recovery of chemical flooding in primary-minor layers was affected by the type of oil displacing agent and the slug size. The larger the slug size and the higher the injection pressure, the better the enhanced oil recovery. Given the ability of enhancing recovery efficiency and reducing cost, high-concentration polymer flooding was proved to be the most effective method.

\section{References}

Cui W, Zhao J C, Wang C Z, et al. Effect of surface treatment on rheological behavior of glass bead/hydroxyl terminated polybutadiene suspensions. Journal of the Central South University of Technology. 2008. 15(1): 158-162

Dong Z X, Lin M Q, Wang $\mathrm{H}$, et al. Influence of surfactants used in surfactant-polymer flooding on the stability of Gudong crude oil emulsion. Petroleum Science. 2010. 7(2): 263-267

Dong $\mathrm{Z} \mathrm{X,} \mathrm{Wu} \mathrm{Z} \mathrm{L,} \mathrm{Lin} \mathrm{M} \mathrm{Q,} \mathrm{et} \mathrm{al.} \mathrm{The} \mathrm{influence} \mathrm{of} \mathrm{polymer}$ concentration on the size of the linked polymer coils. Polymeric Materials Science \& Engineering. 2003. 19(4): 159-163 (in Chinese)

Guan H. Numerical simulation of the proper development priorities of the second and third type reservoirs. Journal of Daqing Petroleum Institute. 2006. 31(1): 112-115 (in Chinese)

Guo W K, Cheng J J and Liao G Z. Present situation and direction of tertiary recovery technique in the future in Daqing Oilfield. Petroleum Geology \& Oilfield Development in Daqing. 2006. 21(3): 1-6(in Chinese)

Li D S and Lu S L. The effect of biosurfactant on the interfacial tension and adsorption loss of surfactant in ASP flooding. Colloids and Surfaces A: Physicochemical.Engineering Aspects. 2004. 15(1): 5360

Li G Z, Mu J H, Li Y, et al. An experimental study on alkaline/surfactant/ polymer flooding systems using nature mixed carboxylate. Chinese Journal of Chemical Engineering. 2000. 9(1): 219-229

Lu X G and Zhang K. Degradation action of the anaerobic bacteria and 
oxygen to the polymer. Chinese Journal of Chemistry. 2008. 26(4): $770-774$

Shao C J, Yang Z P, Zhou G G, et al. Pore network modeling of water block in low permeability reservoirs. Petroleum Science. 2010. 7(3): 362-366

Shi L T, Ye Z B, Zhang Z, et al. Necessity and feasibility of improving the residual resistance factor of polymer flooding in heavy oil reservoirs. Petroleum Science. 2010. 7(2): 251-256

Steve S and Randy P. Salt free: A history of a chemical application to inhibit salt formation in a North African field. Paper SPE 102627 presented at SPE Annual Technical Conference and Exhibition, February 28-March 2, 2007, Houston, Texas

Wang D M and Zhang J C. Foreign Tertiary Recovery Technology. Shanghai: Shanghai Jiaotong University Press. 1992. 57-59 (in
Chinese)

Xia H F, Wang D M, Wang G, et al. Elastic behavior of polymer solution to residual oil at dead-end. Acta Petrolei Sinica. 2006. 27(2): 72-75 (in Chinese)

Yang E L and Song K P. Study of injection rate of third level formation with polymer flooding in Daqing Oilfield. Oil Drilling \& Production Technology. 2006. 28(3): 45-49 (in Chinese)

Zhao G. The proper injection-production ratio of polymer flooding and UFRYH Q \& Petroleum Institute. 2008. 32(1): 108-111 (in Chinese)

Zhu H J, Zhao C Q, Luo J H, et al. Study on the microstructure of polymer molecule hydrate. Journal of Chinese Electron Microscopy Society. 2005. 24(3): 205-210 (in Chinese)

(Edited by Sun Yanhua) 